\title{
THE SYSTEM OF TRANSITIVITY IN THE WAR ON TERROR DISCOURSE
}

The paper focuses on the presentation of social actors in the discourse of George W. Bush in the period from October 2001 to March 2003. The first part of the paper deals with the theoretical elaboration of the system of transitivity within M. A. K. Halliday's Systemic Functional Linguistics (SFL). In this part of the article, the relevant components of the system of transitivity are introduced and discussed. The focus of the analytical part of the paper is on the representation of social actors in the discourse of the speaker. The aim of the paper is to observe the creation of the "Us" and "Them" camps with the help of the selections in Material processes.

Keywords: Transitivity, political speech, discourse, "Us" and "Them."

\section{Introduction}

Language is used not only in interactions with other people but also in discussions about the world - either the world around us represented by objects, things, typical features and also about the inner perceptions of the world represented by emotions, or assumptions. When the world is looked on from this point of view, the focus is mainly placed on the content of communication [1]. The area of grammar of a clause which is associated with the content of a message, conceptualisation and depiction of the world is in functional linguistics referred to as transitivity. In M. A. K. Halliday's Systemic - Functional Linguistics (SFL), language is a resource for making meaning and it fulfils three metafunctions: ideational, interpersonal and textual.

The objective of this article is to present descriptions of the text's ideational function and to relate these features and descriptions to the ideologies that they help to realize. Another objective is to focus on the exploration of linguistic presentation of what political actors view as the real world and on how particular fields of social activity associated with actors are represented in discourse. In the first part of the article, the system of transitivity and its main aspects will be briefly introduced. This theoretical introduction of the aspects of the system of transitivity will serve as a point of departure for further analysis of actual instances from political discourse of George W. Bush. The speeches that are analyzed cover the period of the rhetorical preparation for the military operations in Afghanistan and in Iraq. The speeches present instances of interventionist discourse and their nature may be described as "call to arms" as well.

The system of transitivity is the element of the lexicogrammar which realizes the ideational metafunction. Halliday [2, p. 53] claims that the ideational function of a clause deals with "the transmission of ideas"; and that "the role of the ideational function is to introduce the schemes of 'experiences' or, in the broadest sense, 'processes', which typically include "actions or events of consciousness and relations" (ibid.). Halliday [3, p. 66] also observes that the ideational function is "concerned with the content of language, its function as a means of our experience, both of the external world and of the inner world of our own consciousness." Thus, the ideational metafunction may be useful in observing of how meaning is construed and how events, and the world around us are represented.

Halliday (quoted in [4, p. 34] suggests that "it is through this function that the speaker or writer embodies in language his experience of the phenomena of the real world; and this includes his experience of the internal world of his own consciousness [...] and also his linguistics acts of speaking and understanding."

Similarly, Martin and Rose [5, p. 66] argue that "ideation focuses on the 'content' of a discourse: what kinds of activities are undertaken, and how participants in these activities are described, how they are classified and what they are composed of. Ideation is concerned with how our experience of 'reality', material and symbolic, is construed in discourse" (emphasis in original). Thus, the analysis of selection of the patterns of transitivity may present an effective tool in uncovering various ideological positions in discourse.

The system of transitivity is concerned with how reality (including fictional and mental reality) is presented in language. Its main elements are the processes in texts and the types of participants and circumstances that are usually identified with them. One of the most important assumptions behind the use of this concept is the notion that transitivity is "concerned with

\footnotetext{
* Marek Hampl

Department of English Language and Literature, Faculty of Humanities, University of Zilina, Slovakia

E-mail: marek.hampl@fhv.uniza.sk
} 
the transmission of ideas" $[6$, p. 88]. According to Halliday [2, p. 101], if we are exposed to seeing something, "perceptually the phenomenon is all of a piece but when we talk about it, we analyse it as a semantic configuration", which means that it has to be depicted as a certain composition of meaning.

\section{Analytical approach}

In order to investigate the representation and construction of various social actors [7] in political speeches with the help of the system of transitivity, I will look at the processes by which the nature of identities such as "Us" and "Them" (or enemy) was created and presented in political speeches.

For this purpose, the concepts of Actor, Process, and Goal from the transitivity theory of Systemic - Functional Linguistics (SFL) are used as analytical tools. I will look at how the clauses are arranged in order to present action and events. I will also discuss how the theory is relevant to exposing ideology in political discourse in general and to the specific instances of the analysis of political discourse. For the exemplification, I will examine data from political texts to show how these analytical tools can be used in this type of text analysis. Finally, there will be a discussion about the portrayal of political actors and groups of individuals in discourse. Analysing the system of transitivity in political speeches enables us to understand the fact how ideologies are created in political discourse. Therefore, analysing of the system of transitivity enables us to observe how linguistic framework of a text constructs particular ideologies, in this case, the creation of the dichotomy "Us" vs "Them."

\section{Defining the sytem of transitivity}

Transitivity is an essential element of the ideational function of language and it examines how meaning is present in a clause. It primarily deals with how meaning is present in a clause, and with how concepts or thoughts are conveyed and communicated.

According to [2, p.101], the real world as we perceive it is composed of various types of processes:

[a] fundamental property of language is that it enables human beings to build a mental picture of reality, to make sense of their experience of what goes on around them and inside them. Here again the clause is the most significant grammatical unit $[\ldots]$ because it is the clause that functions as the representation of processes. [...] Our most powerful conception of reality is that it consists of "goings-on": of doing, happening, feeling, being. These goings-on are sorted out in the semantic system of the language and expressed through the grammar of the clause.
According to [8, p. 106], the transitivity system "construes the world of experience into a manageable set of PROCESS TYPES." It is concerned with how reality is presented in language. Halliday [3, p. 134] defines transitivity as

the set of options whereby the speaker encodes his experience of the processes of the external world, and of the internal world of his own consciousness, together with the participants in these processes and their attendant circumstances; [...] Transitivity is really the cornerstone of the semantic organization of experience.

Thus, the analysis of the system of transitivity may indicate how linguistic selections in texts present various actions, events and states. Transitivity, according to Halliday (in [9, p. 159]) includes the whole clause, and it "refers to the "content" or factual - notional structure of the clause in its entirety." Halliday (quoted in [9, p. 159]) defines transitivity as the "representation in language of PROCESSES, the PARTICIPANTS therein, and the CIRCUMSTANTIAL features associated with them."

\subsection{Transitivity - concepts and terms}

It is vital to clarify particular concepts and terms associated with the system of transitivity. In spite of the term "transitivity", this area deals with more elaborate elements than with just simple difference between transitive and intransitive verbs. In this part of the article, the main concepts and terms associated with transitivity will be described, and also the types of processes. This difference in terms of syntax overlooks essential distinctions with regards to meaning within particular types of verbs and clauses. Halliday's model is highly semanticized and it investigates deeper elements of the connection between verbs and the phrases connected with them. The system of transitivity does not pay attention explicitly to verbs as being syntactic category, but on the types of processes represented in a clause, and on how meaning is present, realised and expressed in a clause.

Halliday (quoted in [9, p. 159]) argues that the term process is "understood in a very broad sense, to cover all phenomena to which a specification of time may be attached - in English, anything that can be expressed by a verb: event, whether physical or not, state, or relation." The complete representation of processes, on the basis of this definition, includes the relationships between a particular process and the participants included in it. The participant can be seen as a linguistic representation of abstract, or inanimate objects, and of human beings as well. The main features and their components (such as participants, processes, circumstances) are the essential elements of ideational meaning, in spoken as well as in a written form of communication. 


\subsection{Types of processes and respective participants associated with them}

Within semantic properties of a text, it is noticeable what types of predicates are present: these are expressions referring to actions, states, processes. Predicates (and participants connected with them) perform the primary responsibility for the presentation of events and actions to which text refers. Halliday (quoted in [9, p. 20]) argues that "functions such as 'agent' and 'process' are significant in relation to the meaning potential of the ideational element in language." According to Bloor and Bloor [10, p. 109] "the process centers on that part of the clause that is realised by the verbal group, but it can also be regarded as what "goings-on" are represented in the whole clause." Simpson [6, p. 88] notes that "processes can be classified according to their main features: they represent actions, speech, states of mind or simply states of being."

Halliday [2, p. 101] argues that "transitivity specifies the different types of processes that are recognized in the language, and the structures by which they are expressed." The main components of the transitivity system are Material, Mental and Relational processes. These are the three main types of processes in the English transitivity system and they are differentiated on the basis of the fact whether they represent sensing, actions, or being. In addition, there are, according to Thompson [1, p. 96], "three less central types which can be distinguished on the basis of the usual combination of semantic and grammatical criteria." These processes are Behavioural, Verbal, and Existential Processes.

For the objective of the analysis, processes are essential, as they deal with forms of verbs and with the character of particular "doings." Processes (and the participants associated with them) have the principal responsibility for expressing the actions and states to which texts refer. The processes will illustrate important aspects about the manner in which actors and the world are presented in any type of discourse, and also in political speeches. There are three elements of the grammar of the clause, including a process. Halliday [2, p. 101] suggests that "the basic semantic framework for the representation of processes is very simple. A process consists potentially of three components:

(i) the process itself;

(ii) participants in the process;

(iii) circumstances associated with process."

Halliday [2, p. 102] goes on to argue that the notions of "process, participant and circumstance are semantic categories which explain in the most general way how phenomena of the real world are represented in linguistic structures." The focus of transitivity is placed predominantly on the fist two elements, i.e. on the processes and participants.

\subsection{Participants}

Each process is associated with participants - they are essential in processes - it is difficult to think about an event without participants - there should be at least one participant involved. Participants take the forms of nouns phrases (generally subjects) direct objects, or indirect objects and they involve entities, persons, abstractions, or things. Young and Fitzgerald [11, p. 39] propose a scheme which illustrates the above presented semantic framework for the representation in discourse.

\begin{tabular}{|ll|}
\hline Who and whom $=$ Participants & (nouns/ pronouns) \\
Is doing what $=$ Process & (verbs that realize action/ states) \\
When, where, $=$ Circumstances & (adverbs, prepositional and \\
& adverbial phrases) \\
And how & \\
\hline
\end{tabular}

\subsection{Material processes}

This type of process is characterized by the involvement of physical action or involvement of an event. A typical interpretation of a verb is that of "doing word."

Thus, "figures of 'doing' represent material actions: "what people do or what happens" [5, p. 72]. Halliday (quoted in [9, p. 161]) entitles Material processes also "action clauses" (related only to Material, but also to Mental and Relational processes). Halliday and Matthiessen [12, p. 170] state that in Material processes, "things happen and people or other actors do things, or make them happen." Examples of verbs that realize Material processes are provided by verbs such as "kick", "kill", "attack", etc. The "doer" of this category of activity is referred to as "Actor" and this entity can be animate or inanimate. The Actor "does the deed" [13, p. 224] or performs the action and is responsible for causing the action or event and thus, Actors are considered powerful entities - as they are, according to [13, p. 224] "the source of energy bringing about the change." The second participant is labeled as "Goal" and this is because the action, or activity is directed at this entity, which is the most affected. Despite the fact that Goals are "autonomous" participants, they are usually the least powerful entitites because the activity of Actors is performed on them. Actor and Goal are the two regular participants in clauses associated with Material processes. The aim of the analysis of Material processes is to expose who is presented as the most powerful entity in discourse. E.g., if there are Actors and Goals (represented as affected participants), Actors are powerful entities, initiators of actions and usually those responsible for particular "doings." A brief illustration of a Material process is presented below, taken form the discourse of George W. Bush (Sept. 15, 2001). 


\begin{tabular}{|l|l|l|}
\hline We & will find & them \\
\hline Actor & Pr.: material & Goal \\
\hline
\end{tabular}

\section{The process of analysis}

\subsection{The patterns of transitivity in political speeches of George W. Bush}

In order to analyze the patterns of transitivity in political speeches, the focus will be placed on the clauses from the political speeches that illustrate the presentation of social actors, actions and events.

The initial step in the organizing of the patterns of transitivity was to collect "the clauses in which each entity or group of entities in the text is represented in a particular participant role" $[14$, p. 18]. When certain patterns are extracted from a set of texts of the same type, they enable general observations about the manner in which important participants in discourse are portrayed. The presentation of the clauses with respective participants and processes will be followed by discussion about their representation in the discourse of the speaker. The tables below (with respective Material processes) summarize the participants and actors presented in the discourse of George W. Bush. The patterns in Material process clauses will be examined - the aim of these examinations in the selections of the system of transitivity is to explore how these selections create particular presentation of reality for the audiences in the domestic and in international context as well.

\subsection{Material processes}

The meanings about the actions in discourse (the action of enemies and the actions of the United States and its allies) can be most powerfully conveyed with the help of Material processes. As Material processes are regularly employed in the discourse of the speaker, it is vital to discuss the aspect of power related to participants in the discourse. The Tables 1 and 2 below illustrate the actions taken by the Actors in discourse of George W. Bush - the actions taken by the enemies and by the United States, respectively.

Political leaders, when discussing their enemies or opponents and their actions usually do not make assertions that attribute dynamic grammatical descriptions to them. However, in the discourse of George W. Bush, the intense and utterly unfavourable description of the "other" with the help of Material processes suggests that the world - under the influence of the enemy's actions is a more insecure place.

The enemy is presented as being active - it is presented in specific and purposeful actions. However, their activities are related to destructive actions and are inhuman in their nature. The speaker constructs the ideological polarization between "Us" and "Them" on the basis of the destructive behaviour of the enemies. This is realized by locating of the agency, negatively evaluated Material processes and Goals of the actions of the enemies.

The presentation of enemies in their roles of Actors and their attempts to kill innocent people construct the enemy as a threat to the civilized world. The Goals of the enemies' actions are realized through Material processes or "doings" performed over living entities ("thousands of our citizens", "thousands of innocent people", "fellow Muslims") [15].

According to [6, p. 109], within Material processes, "lexical choices are just as strong an indicator of the respective political stances adopted." In the clauses within which enemies are presented, the speaker employs a number of words which have affective connotations and most of these words have negative evaluations of the activity to which they refer. Therefore, the negative evaluation can be observed in clauses with Material processes such as "kill", "violate" as they are usually negatively perceived in most contexts. Thus the Actors in the clauses are evaluated negatively in the processes that they perform. The choices of tense in verbal groups in clauses (3), (4), (6) (simple present suggests habitual action) suggest that the behaviour of the

The Enemy as Actor in Material Processes in the Discourse of George W. Bush

Table 1

\begin{tabular}{|c|c|c|c|c|}
\hline No. & Date & Actor & Process: Material & Goal \\
\hline 1 & Nov. 21, 01 & They & have killed & thousands of our citizens \\
\hline 2 & Nov. 21,01 & They & seek & weapons of mass destruction \\
\hline 3 & Nov. 10,01 & They & kill & thousands of innocent people \\
\hline 4 & Nov. 10,01 & They & Kill & fellow Muslims \\
\hline 5 & Nov. 6, 01 & They & are seeking & chemical, biological and nuclear weapons \\
\hline 6 & Oct. 10,01 & They & plan, promote, and commit & murder \\
\hline 7 & Nov. 10,01 & The terrorists & are violating & tenets of every religion... \\
\hline 8 & Oct. 2,02 & The regime & has developed & weapons of mass death \\
\hline 9 & Oct. 2,02 & It & has sponsored and sheltered & terrorists; \\
\hline 10 & Oct. 7, 02 & It & is seeking & nuclear weapons \\
\hline
\end{tabular}


The USA as Actor in Material Processes in the Discourse of George W. Bush

Table 2

\begin{tabular}{|c|c|c|c|c|}
\hline No. & Date & Actor & Process: Material & Goal \\
\hline 1 & Jun. 24,02 & We & defend & freedom \\
\hline 2 & Dec. 11,01 & We & will defeat & the enemies of freedom \\
\hline 3 & Apr. 17,02 & We & defend not only & our precious freedoms... \\
\hline 4 & Oct. 7,02 & We & will defend & our freedom \\
\hline 5 & Mar. 19,03 & We & defend not just & America or Europe \\
\hline 6 & May 23,02 & We & will defeat & the enemies of freedom \\
\hline 7 & May 23,02 & We & will confront & the threat of terrorism \\
\hline 8 & Oct. 8,01 & We 01 & terror \\
\hline 9 & Oct. 17,01 & We & will defeat & these evil ones \\
\hline 10 & Nov. 21,01 & We &
\end{tabular}

enemy is constant and typical of the terrorists, which contributes to their demonization. The enemies are construed as dynamic participants who have the ability to affect other enitites in discourse and therefore, they have to be confronted.

In all of the Material processes above, the United States takes the role of the Actor, and the processes are classified as those of the action type. The United States is in all of these clauses firmly in control of all action that it performs - the clauses illustrate Material processes that are intented. In the examples above, the speaker presents a firm resolution to act and to defend values such as freedom, or to defeat "the enemies of freedom" or "global terror" that are positioned as Goals in the clauses and are essential for the United States.

In these clauses, the speaker reassures the recipients of his discourse that these values (especially freedom) are under the control of Actors. At the same time, the speaker presents the power and resolution of the USA to act against "global terror", "terrorist organizations", "enemies of freedom", or "the threat of terrorism." The use of the future tense in certain clauses (e.g., in clauses 2, 3, 5-9) solidifies the resolution to act and gives the power to act in the near term. The use of "will" may be observed in threats or promises, and the speaker, on the basis of his institutional status can issue such threats as he has capabilities to carry out the action that would involve the use of power. The speaker's discourse also points to the ability of the USA to confront the enemy and win - this can be observed in the selection of Material processes and Goals of the actions of the "We" group.

Overall, in selecting the patterns of transitivity in his discourse, the President employs an effective way of creating "otherness" he presents the enemy by pointing to, e.g., physical actions over people that they commit, and also negatively evaluates the actions of "Them." Thus, he creates a viewpoint and presentation of the events that empower "Us" in the action against the enemy.

\section{Conclusion}

Transitivity allows to analyse how, by selecting and preferring particular processes to others the author (or presenter) of the text is able to highlight specific meanings in discourse and to restrain other meanings. The analysis of the patterns of transitivity in discourse offers a tool for exploring of how the organization of texts encodes certain system of ideas.

This paper has discussed the suitability and relevance of the system of transitivity within Systemic - Functional Linguistics (SFL) in uncovering ideological positions and attitudes of the speaker - more specifically, the ideology of polarization into two opposing camps - "Us" and "Them." The analysis of representation of social actors and of Material processes associated with them in discourse through the system of transitivity may indicate how political actors (in this case George W. Bush) in their discourse develop and sustain the ideological picture of the world.

\section{Corpus of Speeches delivered by George W. Bush}

October 8, 2001 Remarks by the President from Speech at the Swearing-in Ceremony for Governor Thomas Ridge

October 10, 2001 Remarks by the President from Speech Unveiling “ Most Wanted“ Terrorist List

October 17, 2001 Remarks by the President from Speech to the California Business Association

November 6, 2001 Remarks by the President from Speech to the Warsaw Conference

November 10, 2001 Remarks by the President from Speech to the United Nations General Assembly

November 21, 2001 Remarks by the President from Speech to Military Personnel at Fort Campbell

December 11, 2001 Remarks by the President from Speech to Citadel Cadets

April 17, 2002 Remarks by the President from Speech to the George C.Marshall ROTC Award 
Seminar on National Security at the Virginia Military Institute

May 23, 2002 Remarks by the President from Speech to the German Bundestag

June 24, 2002
Remarks by the President from Speech at Ceremony Honoring Port Authority Heroes
October 2, 2002

October 7, 2002

March 19, 2003
President, House Leadership Agree on Iraq Resolution

Remarks by the President from Speech at the Cincinnati Museum Center

Presidential Address the Nation on the Commencement of Military Operations Against Iraq

\section{References}

[1] THOMPSON, G.: Introducing Functional Grammar. London : Arnold, 1996.

[2] HALLIDAY, M. A. K.: An Introduction to Functional Grammar. London : Edward Arnold, 1985.

[3] HALLIDAY, M.A.K.: Explorations in the Functions of Language. London : Edward Arnold, 1973.

[4] DE JOIA, A., STENTON, A.: Terms in Systemic Linguistics. A Guide to Halliday. London : Batsford Academic, 1980.

[5] MARTIN, J. R., ROSE, D.: Working with Discourse: Meaning Beyond the Clause. London and New York : Continuum, 2003.

[6] SIMPSON, P.: Language, Ideology and Point of View. New York : Routledge, 1993.

[7] VAN LEEUWEN, T.: The Representation of Social Actors. Caldas-Coulthard, Carmen Rosa and Malcolm Coulthard (eds.). Text and Practices: Readings in Critical Discourse Analysis. London : Routledge. pp. 32-71, 1996.

[8] HALlidAY, M. A. K.: An Introduction to Functional Grammar (2 ${ }^{\text {nd }}$ edition). London : Edward Arnold, 1994.

[9] KRESS, G. (ed.): Halliday: System and Function in Language. London : Oxford University Press, 1976.

[10] BLOOR, T., BLOOR, M.: The Functional Analysis of English. A Hallidayan Approach 2nd Edition. London : Arnold, 2004.

[11] YOUNG, L., FITZGERALD, B.: The Power of Language. How Discourse Influences Society. London : Equinox Publishing Ltd., 2006.

[12] HALlidAY, M. A. K., MATTHIESSEN, C. M. I. M.: An Introduction to Functional Grammar (3 ${ }^{\text {rd }}$ edition). London : Arnold, 2004.

[13] HALLIDAY, M. A. K.: Halliday's Introduction to Functional Grammar (4th edition), revised by Matthiessen, C. M. I. M. Oxon : Routledge, 2013.

[14] THOMPSON, G.: From Process to Pattern: Methodological Considerations in Analysing Transitivity in Text. Carys Jones and Eija Ventola (eds.), From Language to Multimodality. New Developments in the Study of Ideational Meaning, pp. 17-33. London : Equinox Publishing, 2008.

[15] BUTT, D., LUKIN, A., MATTHIESSEN, C.M.I.M.: Grammar, the First Covert Operation of War, Discourse and Society, vol. 15 (2-3), 2004, 267-290. 